\title{
LA PUESTA EN VALOR DEL ARTE RUPESTRE DEL VALLE DEL CÔA (PORTUGAL) (1)
}

\author{
THE MANAGEMENT OF THE CÔA VALLEY ROCK ART (PORTUGAL)
}

JOÃO ZILHÃO (*)

\section{RESUMEN}

El arte rupestre del valle del Côa habría quedado completamente sumergido si se hubiera autorizado la continuación de la construcción de la gran presa de Foz Côa, iniciada en 1992. El proyecto de la presa fue interrumpido en 1995, estableciéndose en ese área un parque arqueológico de $200 \mathrm{~km}^{2}$, que está ahora legalmente protegido al mas alto nivel como Monumento Nacional. El acceso público a sitios seleccionados está organizado mediante recorridos en vehículos cuatro por cuatro de grupos de ocho personas acompañados por guías preparados adecuadamente en arqueología y estudios de arte rupestre. Los Centros para los visitantes se establecieron en casas tradicionales restauradas situadas en pueblos en torno a la periferia del parque. Se va a crear un museo de arte y arqueología y servicios de investigación asociados en el emplazamiento de la presa ahora abandonada. La importancia universal del patrimonio cultural del valle y el carácter de hito de la decisión del gobierno portugués de preservarlo a pesar de la enorme pérdida financiera que supone han sido ampliamente alabadas. Como resultado, el arte rupestre prehistórico del Côa fue incluido en la Lista del Patrimonio Mundial en diciembre de 1998.

\footnotetext{
ABSTRACT

The Côa valley rock art would have been completely submerged if construction of the large Foz Côa dam, began in 1992, had been allowed to continue. The dam project was

*) Instituto Português de Arqueologia. Av. da Índia, 136 1300-300 Lisboa. Portugal. Correo electrónico: jzilhao@ipa.mincultura.pt

El artículo fue remitido en su versión final el 26-IX-2000.

(1) Este texto corresponde a la versión castellana de una comunicación presentada por el autor al Coloquio Internacional «L'art paléolithique à l'air libre. Le paysage modifié par l'image», realizado en Tautavel, Francia, entre el 7 y el 9 de octubre de 1998, bajo la dirección de Dominique Sacchi.

La traducción del original en francés ha sido realizada por $\mathrm{M}^{\mathrm{a}}$ Isabel Martinez Navarrete y revisada por el autor.
}

halted in 1995 and $200 \mathrm{~km}^{2}$ archaeological park was established in this area, which is now legally protected at the highest level as a National Monument. Public access to selected sites is organized through four-wheel drive tours of groups of eight people accompanied by guides appropriately trained in archaeology and rock art studies. Visitor Centers were set-up in restored traditional houses located in the villages around the periphery of the park. A museum of art and archaeology and associated research facilities is to be established at the site of the now abandoned dam. The universal importance of the valley's cultural heritage and the landmark nature of the Portuguese government's decision to preserve it in spite of the huge financial loss involved have been widely acclaimed. As a result, the prehistoric rock art of the Côa was included in the World Heritage List in December 1998.

Palabras clave: Arte paleolítico. Patrimonio mundial. Conservación y gestión del patrimonio arqueológico.

Key words : Palaeolithic art. World heritage. Conservation and management of archaeological heritage.

\section{INTRODUCCIÓN}

El descubrimiento del arte paleolítico del valle del Côa data de 1991, cuando fue hallada la roca 1 de Canada do Inferno (Fig. 1). Sin embargo, sólo en noviembre de 1994, cuando muchas otras rocas grabadas habían sido ya encontradas en el mismo lugar, su existencia fue anunciada oficialmente por las autoridades responsables. En las semanas siguientes, una rápida sucesión de nuevos descubrimientos amplía la extensión de la parte decorada del valle en varios kilómetros (Baptista y Gomes, 1995; Rebanda, 1995).

En esta época, sin embargo, la construcción por la EDP (Electricidade de Portugal) de una gran 

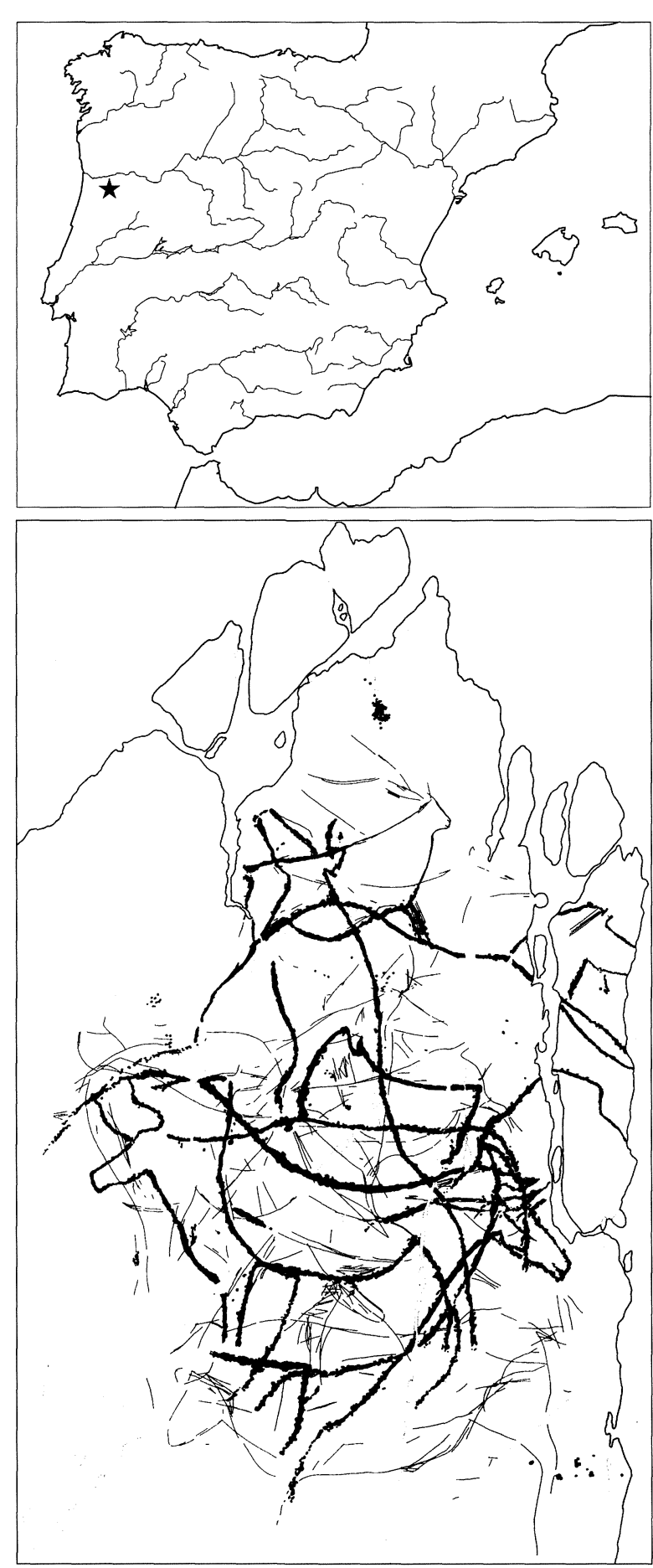

Fig. 1. Localización del valle del Côa (Portugal) en la Península Ibérica y roca 1 de Canada do Inferno.

presa, sólo algunos centenares de metros río abajo de Canada do Inferno, había ya comenzado. Si continuaba, la consiguiente inundación del valle habría implicado la sumersión total del arte rupestre bajo decenas de metros de agua. Felizmente, la campaña nacional e internacional que, durante un año, había pedido la paralización del proyecto para que este muy importante patrimonio arqueológico pudiera ser estudiado y preservado, tuvo éxito: el nuevo gobierno portugués elegido el 1 de octubre de 1995 anunció, a principios de noviembre, que el proyecto de la presa sería abandonado, y que iba a crearse un parque arqueológico en la región para encuadrar la investigación y destacar el valor de este arte. Y, en efecto, tras algunos meses de trabajo de preparación el PAVC (Parque Arqueológico do Vale do Côa) abrió al público a principios de agosto de 1996 (Zilhão, 1998).

\section{EL MONUMENTO}

En el valle del Côa y en las laderas adyacentes de la orilla izquierda del Duero se conoce hasta la actualidad mas de una veintena de conjuntos de rocas grabadas, distribuidas a lo largo de unos $17 \mathrm{~km}$ (Zilhão, 1997; Zilhão et alii, 1997; Baptista, 1999). En su mayoría, se trata de paneles decorados en la época paleolítica, aunque otros periodos estén igualmente bien representados. Es el caso, en particular, de la Edad del Hierro, pero también del Neolítico, del Calcolítico y de los periodos históricos (siglos XVII-XX) (Lám. I).

Estimaciones basadas en el número de paneles ya inventariados que contienen motivos paleolíticos permiten situar bien en mas de un millar el número de figuras que pertenecen a este periodo. Las especies mas representadas son el uro, el caballo, la cabra montés y el ciervo. La ausencia de especies euro-siberianas conocidas en el arte parietal de la región franco-cantábrica (reno, mamut, rinoceronte lanudo, bisonte) es un hecho totalmente normal, si se considera que, en la época, son desconocidas al sur del Ebro.

Las técnicas de ejecución comprenden el piqueteado, la incisión fina, la abrasión y el raspado, a menudo en asociación. La incisión fina es utilizada, sobre todo, para las figuras de pequeño tamaño (hasta $15-20 \mathrm{~cm}$ ), mientras que la gran mayoría de las figuras de tamaño mediano o grande (entre 50 $\mathrm{cm}$ y $2 \mathrm{~m}$ ) tienen contornos piqueteados o raspados. Restos de pintura roja se han identificado en los grandes toros del conjunto de Faia, sugiriendo que, en origen, las representaciones paleolíticas del valle habían sido tratadas cromáticamente. El descubri- 


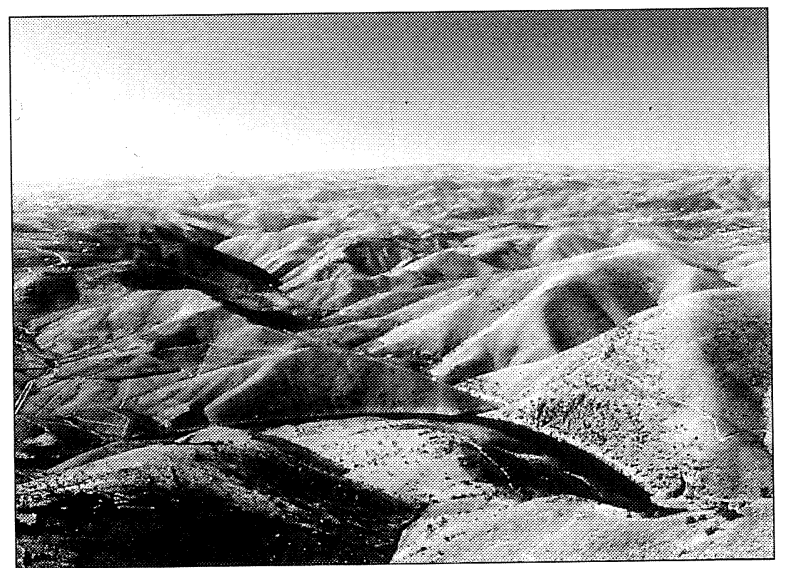

A
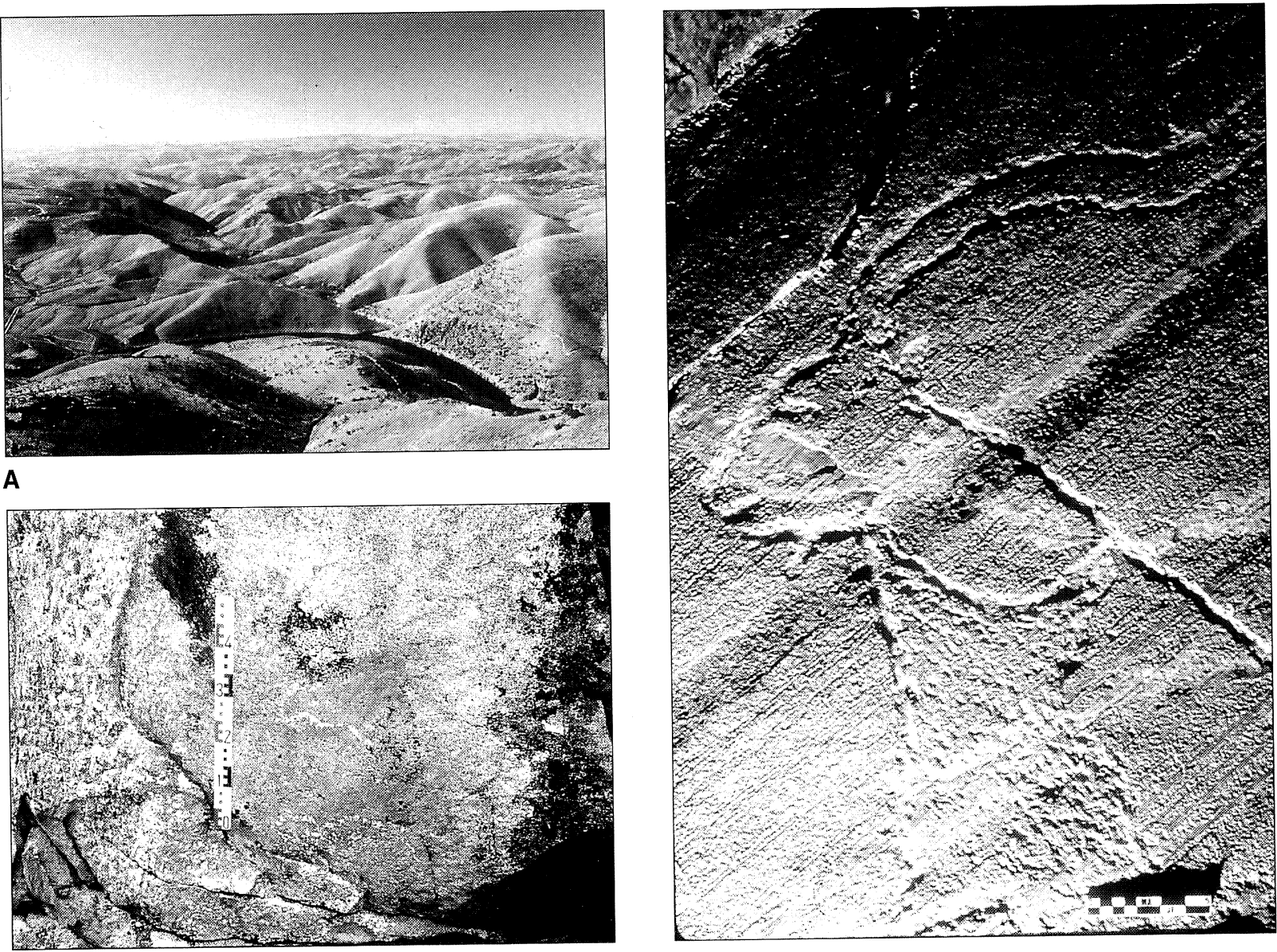

C

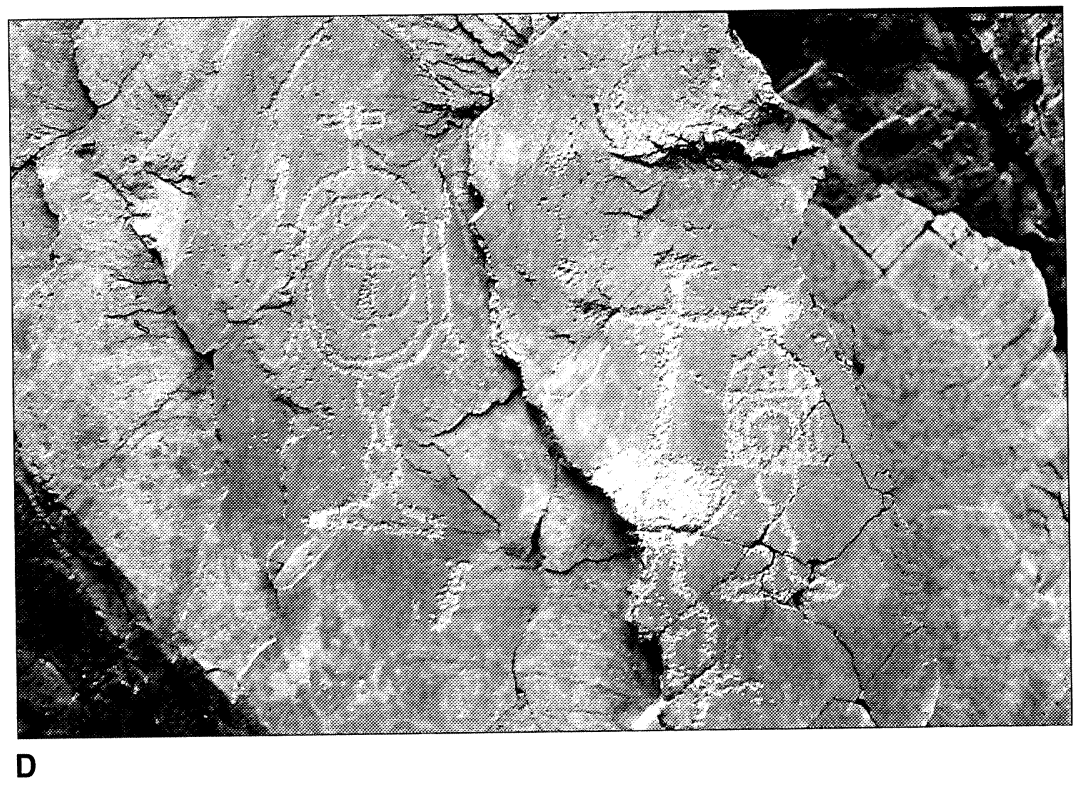

Lám. IA) Vista del valle del Côa frente a la zona de la desembocadura del río de Piscos y de la Quinta de Ervamoira. B) Cabra montés piqueteada paleolítica de Rego da Vide. C) Zoomorfos de estilo neolítico pintados en rojo de Faia. D) Motivos religiosos piqueteados del siglo Xvil de Canada de Inferno. 
miento de restos de pigmentos (ocre rojo y amari1lo, manganeso) en los lugares de habitación contemporáneos del arte identificados en la región desde 1995 concuerda bien con tal hipótesis.

Desde un punto de vista estilístico, el arte paleolítico del Côa, sobre todo en lo que se refiere a las grandes figuras piqueteadas, presenta una característica particular, rara o desconocida en el arte parietal franco-cantábrico: la yuxtaposición sobre el mismo cuerpo de dos cabezas, a veces de tres, con el propósito de transmitir una idea de movimiento. Lo mas frecuente es el movimiento descendente de la cabeza que se dirige hacia abajo, en una escena de acoplamiento o de abrevadero. La técnica ha sido aplicada sobre todo a representaciones de caballos, aunque también se la conoce entre los uros. Otras veces se trata del movimiento del animal que se vuelve para mirar atrás, técnica que se emplea en cabras monteses, uros y ciervos.

Los dos sitios más importantes (Penascosa/ Quinta da Barca, dos lugares situados frente a frente en la orilla derecha e izquierda, respectivamente, y Canada do Inferno) corresponden a concentraciones de grabados situados sobre los afloramientos rocosos que rodean las mejores playas del valle. Esto nos lleva a creer que se trata de un arte que decora áreas de habitación, incluso si los depósitos de fondo de valle preservados en estos sitios no contienen restos arqueológicos de la misma época. Los trabajos arqueológicos emprendidos en Penascosa indican que esta ausencia es debida a la erosión del fini-Pleistoceno, puesto que la base de la secuencia fluvial ha sido datada en torno al $6000 \mathrm{BP}$. Por el contrario, donde las condiciones geológicas han permitido la conservación de depósitos pleistocenos en situación similar, como en Fariseu, hay paneles ricamente decorados (encontrados en diciembre de 1999) enterrados en una secuencia sedimentaria que contenía capas del Gravetiense y del Proto-Solutrense.

Algunas figuras de gran tamaño, que llegan casi hasta los $2 \mathrm{~m}$ de longitud, como los tres uros que se encuentran aguas abajo de la desembocadura del río de Piscos, no están ciertamente en relación con el hábitat. A la vista de la fuerte pendiente de la ladera y de la altura de las paredes grabadas, esas figuras no podían ser vistas mas que de lejos, lo que sugiere una función de señalización o de marcador del territorio cuya significación exacta ya no puede ser reconstruida. Esta hipótesis está reforzada por el hecho de su emplazamiento, a la entrada del cañón terminal recorrido por el Côa antes de la confluencia con el Duero, unos $5 \mathrm{~km}$ aguas abajo.
Las numerosas figuras de trazo fino que se distribuyen de arriba abajo por las laderas, sobre todo en los conjuntos situados ya sobre el Duero, testimonian comportamientos menos públicos. Desde el punto de vista cronológico, su estilo indica también una edad mas reciente, en su mayoría del Magdaleniense, mientras que la mayoría de las grandes figuras piqueteadas parecen haber sido ejecutadas durante el Gravetiense y el Solutrense.

Estos tres periodos están bien representados en los numerosos sitios de hábitat de la región descubiertos en el marco de un programa de prospección sistemática cuyo objeto es el establecimiento de un contexto arqueológico para el arte rupestre (Zilhão et alii, 1995;Aubry, 1998). Ricos en industria lítica pero pobres en restos orgánicos, debido a la acidez de los suelos, estos sitios cuentan con estructuras bien conservadas, sobre todo, hogares. La datación TL de cantos de cuarzo y de cuarcita quemados en estos hogares ha permitido confirmar de manera independiente las cronologías establecidas primero sobre la base de las características técnicas y tipológicas de las industrias. El estudio de las materias primas ha puesto en evidencia la existencia de redes de contacto, circulación o intercambio a muy gran distancia, a la vista de la presencia de sílex terciarios, cuya fuentes, en las regiones litorales de Portugal, se encuentran a mas de $200 \mathrm{~km}$.

Este conjunto de hechos ha permitido describir el descubrimiento del arte del Côa como un acontecimiento científico capital, cuyas repercusiones son comparables a las provocadas por la revelación de Altamira. Tras los descubrimientos de menor dimensión ocurridos desde 1981 en Portugal, España y Francia, el arte del Côa, por la dimensión del sitio y por su riqueza iconográfica, venía a demostrar que el arte paleolítico al aire libre no era en absoluto la excepción. Al contrario, el hecho de que se haya preservado sólo bajo abrigo en las regiones situadas al Norte de los Pirineos se explica probablemente por factores relacionados con la geología, el clima y la tafonomía. Como es la norma entre los cazadores-recolectores documentados por la etnografía, es verosímil que el arte paleolítico haya representado un sistema de transmisión de información que marcaba los territorios humanos de modo ubicuo y daba una dimensión simbólica a los paisajes de antaño. Contra las interpretaciones reductoras o unívocas basadas en una naturaleza subterránea que se pretende exclusiva, los descubrimientos del Côa coronan una revolución copernicana en nuestra visión de un fenómeno complejo y con significaciones concre-

T. P., 57, n. $^{\circ} 2,2000$ 
tas múltiples que han podido ser de orden económico, social, ideológico o psicológico.

\section{LA PROTECCIÓN LEGAL}

Las diferentes acciones emprendidas desde 1996 para poner en funcionamiento el PAVC han sido enmarcadas en diversas disposiciones legales, entre las cuales las mas importantes son las siguientes:

- la Resolución del Consejo de Ministros n. ${ }^{\circ}$ 4/ 96, publicada en el Diário da República de 17 de enero, que formaliza la suspensión de los trabajos de construcción de la presa;

- la Resolución del Consejo de Ministros n. $.^{\circ} 42 /$ 96, publicada en el Diário da República del 16 de abril, que crea el programa PROCOA, para la promoción de la inversión en la región, definiendo el turismo cultural en torno al patrimonio histórico y arqueológico como eje estratégico para el desarrollo económico de los municipios limítrofes;

- el Decreto-Ley n. ${ }^{\circ} 117 / 97$, publicado en el Diário da República de 14 de mayo, que crea el IPA (Instituto Português de Arqueologia), como dirección general del Ministerio de Cultura responsable de la gestión del patrimonio arqueológico nacional, y el PAVC, como dirección de servicios del IPA con su propio marco de personal y competencias específicas;

- el Decreto-Ley n. ${ }^{\circ} 32 / 97$, publicado en el Diário da República de 2 de julio, que cataloga como Monumento Nacional al conjunto Sítios Arqueológicos no Vale do Rio Côa;

- el Decreto-Ley n..$^{\circ}$ 50/99, publicado en elDiário da República de 16 de febrero, que somete a la aprobación previa del IPA toda modificación significativa del paisaje y del uso del suelo en el interior del área del Parque.

El edificio de protección jurídica del arte rupestre del Côa ha sido coronado con su inclusión en la lista del Patrimonio Mundial de la UNESCO. La candidatura había sido presentada por el gobierno portugués el 24 de junio de 1997 y ha sido aprobada por el Comité del Patrimonio Mundial tras su reunión de Kioto, el 2 de diciembre de 1998, sobre la base de los criterios siguientes:

\section{Criterio i:}

el arte rupestre del Paleolítico superior del valle del Côa es una ilustración excepcional de la rápida expansión del genio creador, en el alba del desarrollo cultural del hombre.

\section{Criterio iii:}

El arte rupestre del valle del Côa saca a la luz, de manera totalmente excepcional, la vida social, económica y espiritual del primer antepasado de la humanidad.

La consolidación del proceso de protección pasa en lo sucesivo, de un lado, por la compra por el Estado de los terrenos que han sido objeto de las medidas de catalogación y, del otro lado, por la definición de un Plan de Actuación en la totalidad del territorio asignado al Parque, cuyo perímetro es de $86,5 \mathrm{~km}$ y cuya superficie es de $208 \mathrm{~km}^{2}$. En los términos de la ley portuguesa, ese plan deberá establecer las normas que permitirán la consecución simultánea y compatible de diversos objetivos económicos, culturales y medioambientales:

- la conservación a largo plazo de las rocas grabadas:

- la visita pública de los sitios mas representativos y accesibles;

- el mantenimiento de las actividades agrícolas tradicionales que han creado el paisaje que enmarca los sitios de arte rupestre;

- el respeto a los hábitats de cierto número de especies protegidas, sobre todo rapaces, que nidifican en el valle.

Desde un punto de vista técnico, la elaboración de este plan se ha completado en el verano del 2000. La discusión pública del plan, la introducción de correcciones que se derivan de ella, y la búsqueda de un consenso político para su aplicación entre los departamentos del gobierno central y las autoridades locales, son las etapas que siguen antes de la aprobación final en forma de ley.

\section{LA ORGANIZACIÓN DE LAS VISITAS}

La definición de la estrategia seguida para la creación del PAVC se ha inspirado en la experiencia de otras regiones donde un turismo de arte rupestre y de arqueología paleolítica se ha desarrollado con éxito, tales como Les Eyzies (Périgord, Francia) oAltamira/Santillana del Mar (Cantabria, España). Esta experiencia indicaba que un turismo cultural como el que existía allí y como el que se quería promover en el valle del Côa:

- no puede existir de manera racional y sostenida más que como complemento de las actividades económicas tradicionales;

- es un proceso a largo plazo que depende en 
gran medida de la iniciativa local y no del intervencionismo milagroso del poder central;

- debe tener como polo de atracción la región en su conjunto, de modo que la belleza de su paisaje y de sus otros monumentos históricos y arqueológicos lleven al visitante a permanecer durante estancias prolongadas.

El sistema de gestión de las visitas a los conjuntos de arte rupestre (Fig. 2) está basado en estos principios (Zilhão, 1998). Tres sitios se distinguen por sus dimensiones, la calidad de las figuras y la grandiosidad del paisaje que los enmarca: Canada do Inferno, Ribeira de Piscos y Penascosa/Quinta da Barca. Por esta razón, son estos tres sitios los que han sido abiertos a la visita pública. La decisión de crear un parque arqueológico sobreentiende como filosofía de conservación que los grabados deben ser mantenidos en el contexto que les da su significación, es decir, que el monumento es el valle. En consecuencia, las intervenciones para resaltar el valor de estos tres sitios han sido reducidas al mínimo. En Penascosa, por ejemplo, simplemente se ha adaptado un viejo corral abandonado como abrigo para los vigilantes que permanecen allí 24 horas sobre 24 , y se han preparado o reparado los senderos recorridos por los visitantes.

Los grabados del valle fueron ejecutados sobre paredes rocosas verticales, en su mayoría orientadas Norte-Sur, es decir, expuestas al este en la margen izquierda y al oeste en la margen derecha. En consecuencia, la visibilidad de los grabados varía de forma considerable a lo largo del día: en Penascosa, por ejemplo, los grabados están a la sombra durante la mañana. Por otro lado, la pátina de los trazos y las numerosas superposiciones hacen a menudo difícil una lectura inmediata de los motivos. La solución adoptada para enfrentar estos problemas ha sido la de no permitir el acceso del público a los sitios mas que como visitas guiadas, que tienen lugar sólo en las horas de mejor visibilidad, y en pequeños grupos de ocho personas como máximo a la vez. Los guías han sido reclutados entre la juventud de la región y han sido objeto de una formación especializada que les permite ayudar al visitante a descubrir por si mismo los motivos y darle la información contextual para la buena comprensión del arte rupestre del valle. Además, el guía presta a cada visitante una carpeta que contiene las fichas explicativas que sirven de soporte gráfico a la lectura e interpretación de las figuras.

La acogida de los visitantes se hace en los Centros de Recepción situados en la periferia del Par-

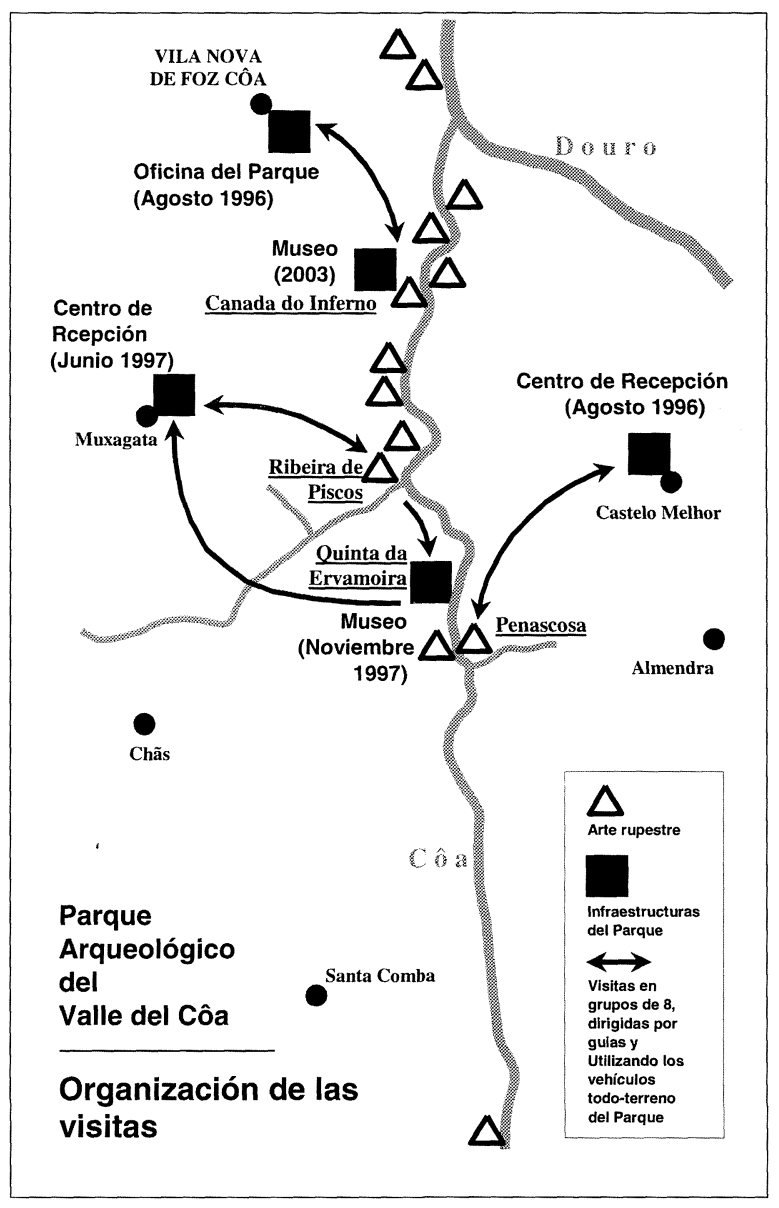

Fig. 2. Sistema de visitas a los sitios con arte rupestre y emplazamiento de las infraestructuras del Parque Arqueológico del Valle del Côa (Portugal), con la fecha de inauguración (efectiva o prevista).

que: en Castelo Melhor para la visita a Penascosa, en Muxagata para la visita a Ribeira de Piscos, y en Vila Nova de Foz Côa, la sede del PAVC, para la visita a Canada do Inferno. Estos Centros tienen todas las infraestructuras necesarias: venta de entradas, de documentos, de recuerdos o de refrescos, instalaciones sanitarias, etc. En el interior, los visitantes pueden también encontrar informaciones sobre el valle y su arte, ya en forma de exposiciones ya en forma de presentaciones HTML en ordenador.

Desde estos Centros salen los vehículos todo terreno del PAVC donde se transporta a los grupos de visitantes, conducidos por los guías. Las distancias implicadas, el horario de trabajo de los guías y la regla de no tener en cada sitio mas que un grupo a la vez imponen por sí mismos límites al número de personas que el parque puede recibir por día: en-

T. P., 57, n. $^{\circ} 2,2000$ 
tre 150 y 200 , con variaciones estacionales dictadas por el aumento de las horas de luz en verano. La existencia de esta limitación queda compensada por la puesta a punto de un sistema de reserva anticipada de visita, obligatoria para las excursiones y grupos escolares.

En noviembre de 1997, se ha inaugurado un Museo de Sitio en la Quinta da Ervamoira. Aunque de iniciativa y propiedad privadas, este museo está integrado en los circuitos del parque. Allí se presenta la arqueología de los sitios romanos del valle, su historia agrícola reciente y la etnografía de la región. El público puede también comprar allí la producción de gran calidad de la propiedad, sobre todo sus muy conocidos vinos.

El futuro Museo del parque está en fase de proyecto, y el comienzo de los trabajos de construcción está previsto para el año 2001. El emplazamiento escogido es el corte abierto en la ladera para recibir la pared de la presa, en la margen izquierda. Al mismo tiempo, los trabajos hidráulicos permitirán devolver al Côa su nivel original en unos $1500 \mathrm{~m}$. En efecto, desde 1983, la parte final del valle está inundada bajo una decena de metros de agua a causa de la construcción de la presa de Pocinho, en el Duero, algunos kilómetros aguas abajo de la desembocadura del Côa. Ello ha implicado la sumersion de numerosos paneles que, tras estos trabajos, volverán a quedar visibles, permitiendo que el sitio de Canada do Inferno pueda ser visitado en su totalidad como extensión al aire libre del Museo.

\section{EL PÚbLICO DEL PARQUE}

Desde su inauguración oficial hace cuatro años, el número de visitantes anuales del PAVC ha sido relativamente constante, entre 20000 y 25000. Una encuesta sociológica realizada por un equipo del ISCTE (Instituto Superior de Ciências do Trabalho e da Empresa, Université de Lisbonne) ha permitido caracterizar al público adulto que visita el parque en verano de la siguiente manera:

- se trata, mayoritariamente, de personas con formación de nivel superior; $45 \%$ tenían un título universitario y $14 \%$ habían asistido a la Universidad sin concluir sus estudios; este hecho explica ciertamente la circunstancia de que alrededor de un $70 \%$ de los encuestados era capaz de identificar correctamente, antes de la propia visita, el periodo histórico al cual pertenecen los grabados (Paleolítico superior);
- se trata, en un porcentaje muy elevado, de personas habituadas a visitar monumentos del patrimonio histórico y arqueológico; el 73\% declararon haber visitado ya sitios arqueológicos, generalmente ruinas romanas, y el 56\% declararon haber visitado una cuarentena de monumentos en los tres años anteriores;

- en un $98 \%$ de los casos este público se declara «satisfecho» de la visita», y en un 64\% «muy satisfecho».

Un estudio de mercado encargado por los promotores de la idea de construir un Parque Temático sobre el arte paleolítico en Vila Nova de Foz Côa ha permitido obtener también informaciones importantes para comprender las actitudes de la opinión pública hacia el parque arqueológico y hacia la decisión de abandonar el proyecto de presa. El estudio, hecho en octubre de 1997, en Portugal y en España, por la empresa Sigma 2, ha permitido concluir que:

- el $97 \%$ de los portugueses (y el 17\% de los españoles) estaban al corriente de la existencia del arte rupestre del Côa; en los institutos de secundaria estos porcentajes eran del $100 \%$ en Portugal y del $41 \%$ en España;

- el $43 \%$ de los portugueses estaban "totalemente de acuerdo" con la decisión de abandonar la construcción de la presa, el 46\% "parcialmente de acuerdo", y sólo el 11\% "totalemente en desacuerdo";

- el descubrimiento del arte rupestre del Côa era un motivo de "gran orgullo" para el 70\% de los portugueses, y de "cierto orgullo" para el $26 \%$.

Estos últimos valores son tanto mas significativos cuanto la controversia política del año 1995 había dividido fuertemente a la población portuguesa. Incluso si, en principio, las encuestas de opinión indicaban una mayoría (55\% contra $30 \%$ en el mes de junio) a favor de la paralización de los trabajos, la confusión causada por la divulgación de estudios pseudo-científicos que ponían en duda la cronología del arte paleolítico del Côa había provocado una erosión de esta mayoría. En enero de 1996, ya después de que el gobierno hubiera decidido preservar el arte y crear el PAVC, había un $28 \%$ de opiniones favorables a la decisión, contra un $39 \%$ que no estaban de acuerdo, habiendo pasado la tasa de indecisos del $15 \%$ en junio de 1995 al 33\% siete meses mas tarde.

Tras cuatro años de funcionamiento, el PAVC se encuentra hoy en una fase de consolidación organizativa y se prepara al salto cualitativo que represen- 
tará la puesta en funcionamiento, prevista para fines del año 2003, del Museo de Canada do Inferno. A partir de este momento, la capacidad de acogida del parque aumentará del máximo de 30000 visitantes al año que existe hoy hasta valores del orden de 200000 a 300 000. Esto permitirá a la iniciativa local emprender las inversiones en infraestructuras turísticas que, de un lado, son necesarias para que este flujo pueda ser mantenido y que, por otro lado, permitirán que el arte del Côa pueda también desempeñar su papel como recurso económico de importancia regional.

\section{BIBLIOGRAFÍA}

Aubry, Th. (1998): “Olga Grande 4: uma sequência do Paleolítico superior no planalto entre o Rio Côa e a Ribeira de Aguiar". Revista Portuguesa de Arqueologia, 1 (1): 5-26.

REBANDA, N. (1995): Os trabalhos arqueológicos e o complexo de arte rupestre do Côa. Instituto Português do Património Arquitectónico e Arqueológico. Lisboa.

Baptista, A.M. (1999): No tempo sem tempo. A arte dos caçadores paleolíticos do Vale do Côa. Parque Arqueológico do Vale do Côa. Vila Nova de Foz Côa.

BAptistA, A.M. y GomEs, M.V. (1995): "Arte rupestre do Vale do Côa. 1. Canada do Inferno. Primeiras impressões". Trabalhos de Antropologia e Etnologia, 35 (4): 349-422.

ZILHÃo, J. (ed.) (1997): Arte Rupestre e Pré-história do Vale do Côa. Trabalhos de 1995-1996. Relatório científico ao governo da República Portuguesa elaborado nos termos da resolução do Conselho de Ministros no 4/96, de 17 de Janeiro. Ministério da Cultura. Lisboa: 210406.

ZILHÃO, J. (1998): “The rock art of the Côa valley, Portugal. Significance, conservation and management". Conservation and Management of Archaeological Sites, 2 (4): 193-206.

Zilhão, J.; Aubry, Th; Carvalho, A.M.F.; Zambujo, G. y AlmeIDA, F. (1995): "O sítio arqueológico paleolítico do Salto do Boi (Cardina, Santa Comba, Vila Nova de Foz Côa)".Trabalhos de Antropologia e Etnologia, 35 (4): 471-497.

Zilhão, J.; Aubry, Th.; Carvalho, A.F.; Baptista, A.M.; GoMes, M.V. y MeIRELES, J. (1997): “The Rock Art of the Côa Valley (Portugal) and its Archaeological Context". Journal of European Archaeology, 5 (1): 7-49. 